\title{
Organizational Design, Project Selection, and Incentives
}

\author{
by \\ MaRia De PaOla AND VinCENZO SCOPPA*
}

This paper compares benefits and costs related to hierarchical and decentralized organizations in an agency framework. We show that the relative efficiency of hierarchy diminishes in contexts with asymmetric information. When effort is not observable, performance-related pay is required in order to encourage the agent to work hard. With risk-averse agents the use of this incentive system is more costly under hierarchy rather than under decentralization, in that a higher wage is necessary to elicit effort. From the efficiency comparison of hierarchy and delegation, a trade-off emerges between the advantages deriving from the principal's screening activity and the higher agency costs that this induces. (JEL: D 23, L 22, J 33)

\section{Introduction}

A growing body of research shows that the allocation of decisional rights among agents influences the performance of the economic organizations in which they operate. While decisional rights are conferred directly through the ownership of assets, the owners often decide to delegate some power to other persons inside the organization. The allocation of authority influences agents' incentives, the use of the available information, communication costs, errors entailed in the decision process, and so on. Firms are usually interested in conferring decisional power on their employees (even at the cost of some loss of control) because better decisions can be made thanks to their contribution, since they are able to collect raw information directly from the production floor and possess unique knowledge due to their work experience.

A number of recent empirical studies (OSTERMAN [1994], CAROLI, GREENAN, AND GUELLEC [2001], RAJAN AND WULF [2003]) show that, whereas until the seventies the prevailing organizational system in industrialized countries was characterized by a strong centralization of decisional rights, in recent years many firms have adopted a

* We would like to thank for useful comments Giorgio Brunello, Annalisa Cristini, Ferdinando Grossi, Maurizio Franzini, Riccardo Leoni, Paolo Pini, two anonymous referees, and seminar participants at the 2003 AIEL conference (Messina), at the workshop "Luchino Brucchi” (Milan), and at the 2004 EALE conference (Lisbon). The usual caveats apply. Financial support from the Italian Minister for Education, University, and Research (PRIN project 2003) is gratefully acknowledged. 
flat organizational structure with a highly decentralized decision-making process. Emphasis has been placed on the so-called employees' empowerment, which refers both to workers' participation in management and to greater autonomy of workers, who are expected to work without the direction of managers.

The theoretical literature on organizational systems and on the allocation of authority among agents provides interesting insights for the interpretation of this phenomenon. Some authors refer to technological change that, with the development of ICT favoring the transmission and acquisition of information, has allowed the replacement of the superiors' activity with the direct interaction between workers (BOLTON AND DEWATRIPONT [1994], GARICANO [2000]). Other works relate the organizational change to the need of firms to adapt to the increased competition and to the greater variability of the economy by giving more autonomy to employees and making them able to respond more quickly to shocks (AOKI [1986]). Moreover, in the face of increased uncertainty of economic circumstances, the principal, being less able to evaluate the agent's choices, prefers to concede him autonomy and uses incentive contracts to prevent his opportunistic behavior (PRENDERGAST [2002]).

In this paper we analyze the choice of the organizational structure in an agency framework, focusing on the effect of the allocation of decisional power on agents' incentives to provide effort in realizing new projects, such as the introduction of a new product or an innovation in the production process, or the opening of a new branch. Two organizational forms are compared: a decentralized system, in which a subordinate acquires information enabling him to formulate a project and autonomously decides on its implementation, and a hierarchical system, in which the subordinate proposes a project, which can be implemented only if approved by his superior. In both structures the expected value of the project is positively related to the agent's effort. Under hierarchy the probability of implementing good projects also depends on the principal's screening abilities.

Individuals make errors of judgment, in that they sometimes reject profitable projects (Type I errors) and sometimes implement bad ones (Type II errors). With exogenously given levels of effort and ability, hierarchy is more efficient at avoiding Type II errors, but more frequently incurs Type I errors.

In the model we endogenously determine the levels of effort provided by the agent and the principal in activities related to project conception and implementation. Assuming, initially, perfect observability of effort, we show that the optimal agent effort is higher under delegation. The relative efficiency of hierarchy and delegation in terms of total surplus depends, therefore, not only on the relevance of costs deriving from Type I and Type II errors, but also on the principal's screening activity and on the disutility of effort.

Introducing into the analysis asymmetric information, that is, supposing that the agent's effort is not observable by the principal, we demonstrate that the performance of the hierarchical system unambiguously worsens compared to the decentralized structure. In order to encourage the agent to provide effort, we assume that the firm under both organizational forms - adopts a performance-related pay contract, 
whereby the agent's remuneration is directly related to the gross profits deriving from the implemented projects. The benefits and the costs deriving from hierarchy and delegation are compared, showing the effects that the organizational structure produces on incentives.

We point out that under a hierarchical structure, inducing the agent to provide large effort might be more costly for the firm, because both good and bad payoffs are less likely for the agent. Firstly, under hierarchy the agent's effort in realizing a good project will determine a high wage only as long as the principal is able to recognize the true nature of the project. On the other hand, proposing bad projects will not result in a low wage when the principal correctly evaluates the project and refuses it. As a consequence, in order to induce the agent to provide effort, it is necessary to pay him a higher wage when good results are obtained and punish him more harshly for bad outcomes. However, if the agent is risk-averse and it is not possible to force him to pay a fine to the firm in case of bad performance, providing stronger incentives will be costly for the firm, because this implies the payment of a higher expected wage.

Comparing the total surplus obtained under the two organizational forms, we show that the relative efficiency of hierarchy is higher when the agent's risk aversion is lower, when the costs deriving from the implementation of bad projects are higher (Type II errors), or when the expected profits from good projects are lower. However, these advantages are to be compared with the higher agency cost. In the case of a high degree of risk aversion or poor observability of effort, which lead to more severe incentive problems, delegation prevails over hierarchy, implying that for the organization it is optimal to forgo the information signal available to the superior.

The paper is organized in the following way. Section 2 briefly discusses the literature on incentives and the allocation of power within organizations. Section 3 presents the main hypothesis of our model and examines the optimal levels of effort under hierarchy and delegation, assuming perfect information. Section 4 considers the existence of asymmetric information and analyzes the effects produced by performance-related pay contracts on the effort provided under the two organizational structures, showing that eliciting large effort is more costly under hierarchy. In section 5 this aspect is emphasized in a framework with discrete levels of effort, which allows us to represent graphically the efficiency comparison between hierarchy and delegation. Section 6 offers some concluding remarks.

\section{Related Works}

The economic literature analyzing the choice of organizational structure has focused traditionally on the process of communication and the organization of knowledge in production; only recently has a burgeoning literature started to analyze the influence of incentive problems on the allocation of decisional rights.

In the organizational approach, leaving aside incentive problems, the choice between centralization and decentralization emerges from the trade-off existing 
between the optimal use of information available at lower levels, allowed by a decentralized decision-making process, and the advantages of coordination and control, deriving from a centralized structure. The organizational form is aimed at solving information and coordination problems, taking into account the costs of acquisition, processing, and communication of information, delays and errors in decision-making, and advantages from specialization (AOKI [1986], SAH AND STIGLITZ [1986], [1988], RADNER [1992], VAN ZANDT [1999], BOLTON AND DEWATRIPONT [1994], GARICANO [2000]).

In some of these analyses a hierarchy is considered a communication network, while in others the concept of authority - that is, the right to choose among different alternatives - is stressed. AOKI [1986] shows that the delegation of decisional power to agents directly involved in the production process allows better use of local information and tends to prevail when the economic situation is characterized by a high degree of uncertainty and when quick responses to changing technology and environment are required.

SAH AND STIGLITZ [1986] build a very useful framework, in which authority means the right to choose which projects to undertake from a wide set. Assuming that individuals' judgments may lead to errors, they show that the organizational form determines the type of errors that more frequently characterize the decision-making process: hierarchy is more able to reduce the probability of approving bad projects, and decentralization is more apt to prevent the refusal of good projects.

Some recent papers show that the relative merits of hierarchical and polyarchical organizations may change when Sah and Stiglitz's framework is extended to consider the incentives to acquire and generate information and endogenous screening rules. GEHRIG, REGIBEAU, AND ROCKETT [2000] analyze project evaluation realized by organizations, allowing different threshold decision rules across screening units. They show that, since the quality of observations communicated by screening units can differ across organizational forms, the polyarchy always uses all the observations, while hierarchy may optimally choose to rely on a single observation (when signals are not very informative). In fact, under hierarchy, using an additional screening unit has the advantage of collecting additional information, but it decreases the informational value of each observation, since in this setup threshold levels are loosened. As a consequence, if the second effect dominates, it is optimal for hierarchy to use only one observation. The authors show that in this case the polyarchical system always performs better. On the other hand, in contexts in which hierarchies choose to use both signals, the relative advantages of polyarchies and hierarchies depend on market conditions. ${ }^{1}$

\footnotetext{
${ }^{1}$ GERSBACH AND WEHRSPOHN [1998], assuming the presence of a budget constraint that forces the different organizational forms to implement the same number of projects and exogenous screening rules, obtain different results. Because when a project is rejected it is not costly to approve alternative ones, the relevance of Type I errors is reduced and hierarchy always performs better.
} 
Using a similar setup, GEHRIG [2004] considers the incentives of agents to acquire information under different organizational forms, assuming that information is generated by an investment choice. Abstracting from asymmetric information problems, he shows that Sah and Stiglitz's results on the relative performance of the organizational forms can be reversed when the production of information is endogenous. In particular, in some settings decentralized systems can perform better because they may allow greater incentives to generate information, reducing in this way both Type I and Type II errors.

Our work is closely related to this literature: we adopt the framework proposed by Sah and Stiglitz, but, instead of considering an exogenously given project portfolio, we endogenize the generation of information, assuming that the quality of information, and therefore the probability of implementing good projects, depends on the agent's effort. Also, whereas the previously mentioned papers do not consider asymmetric information, we consider the effects of moral-hazard problems on the organizational choice, following a growing body of research that tries to marry the organizational approach to the principal-agent framework (ZABOJNIK [2002], STEIN [2002]). ${ }^{2}$ In fact, one of the main limits of standard agency models is that they unrealistically assume that the agent has private information about his effort, but that he does not possess any specific knowledge about the action that should be pursued, and therefore there is no need for communication between principal and agent, and the allocation of decisional rights does not influence subject behavior and firm performance.

The influence of incentive problems on the organizational form has been initially considered by AGHION AND TIROLE [1997], assuming that subjects placed at different hierarchical levels have divergent private objectives. This implies that the allocation of authority inside the organization influences the importance of agency problems. In AGHION AND TIROLE [1997], the delegation of authority to the agent, which allows him to choose projects that maximize his private benefits, enhances his effort in the acquisition of information concerning projects to be implemented. However, increased agent effort can be obtained only at a cost in loss of control, since the implemented projects do not maximize the principal's payoff. The agent's opportunistic behavior can be (partially) controlled only by conceding him power, since monetary incentive contracts are not considered.

In this paper we use the standard formulation of agency contracts in which the agent's opportunistic behavior can be restrained by the principal through performance-related compensation schemes. While in Aghion and Tirole the agent obtains private benefits from the implementation of some particular projects, in our framework opportunism derives only from the tendency to avoid effort, and performance-related pay contracts, offered to prevent moral hazard, play a crucial role. ${ }^{3}$

\footnotetext{
${ }^{2}$ See also AtHeY AND RoBerts [2001], PRENDERGAST [2002].

${ }^{3}$ Moreover, we consider a hierarchical system requiring unanimous approval, while in AGHION AND TIROLE [1997] decisions are always made by only one agent.
} 
A similar approach is followed by ZABOJNIK [2002]. In his paper, under a centralized system the agent has the task of implementing the project selected by his superior, whereas in a decentralized system the agent works on a project selected by himself. He shows that, if the agent is liquidity-constrained, it may be more costly to induce him to work on the project selected by his superior. This because if the agent thinks, after updating his beliefs through Bayes's rule, that the project has a low probability of success, he will be discouraged from providing effort in the implementation stage. On the other hand, if the agent is free to choose the project that, in his opinion, has more probability of success, stimulating his effort will be less costly, since his expected payoffs are higher.

Zabojnik does not consider Sah and Stiglitz's framework of societal information aggregation, but he interprets hierarchy as a system in which the superior, moving first, simply chooses a project without involving the worker. Whereas he points out the differences in the quality of information available to the two agents (showing that it may turn out optimal to give the decisional power to the subordinate, even if his information is worse than the principal's), we focus on the interplay between the relevance of Type I and Type II errors, incentive contracts, and organizational performance.

The effect of the organizational structure on an agent's incentives to acquire information is also analyzed by STEIN [2002], who considers firms' decisions related to the allocation of funds between different projects and takes into account the distinction between soft (i.e., not verifiable from other agents) and hard information. He shows that when information is soft, decentralization strengthens the agent's incentive to search for information. Since the agent is free to allocate the firm's funds, he knows that his research effort will not be wasted. On the other hand, in the case of centralization the agent is aware that the superior may decide to overturn his decision, making the information he has gathered useless. In contrast, with verifiable information centralization always dominates over decentralization.

In this literature decisional rights can be separated from the ownership of physical assets ${ }^{4}$, and problems related to specific investments analyzed in the property-rights school are not considered (GROSSMAN AND HART [1986], HART AND MOORE [1990]). Following this approach, in our paper we do not consider the role of authority (that is, the residual rights of control) in protecting specific investments from holdup.

\footnotetext{
${ }^{4}$ BAKER, GiBBOnS, AND MURPHy [1999] develop Aghion and Tirole’s analysis, focusing on the credibility of delegation. They assume that the delegation of decisional rights to the agent can only be informal - because the principal is always able to overturn subordinates' decisions - and must be based on self-enforcing implicit contracts. Following AGHION AND TIROLE [1997], we do not consider the problem of the principal's commitment in delegating.
} 


\section{The Model}

We consider a firm composed of a principal (the owner-manager) (she) who hires an agent (he). In each period, the agent's task consists of acquiring information in order to develop a particular project and work on it to increase the probability of successful implementation. Under the decentralized organizational form (delegation), the agent has the right to implement the chosen project, whereas under hierarchy he makes a proposal to the principal, who evaluates it and decides on approval or rejection.

Both the agent and the principal may make errors of judgment, in that sometimes bad projects are erroneously evaluated as good projects, actually yielding a negative payoff, and sometimes good projects are erroneously evaluated as unprofitable. The communication process between the agent and the principal is imperfect, and only the judgments they express about projects can be communicated.

The Agent. The agent collects and processes information with the aim of developing a project $X$. The project's payoff can take only two values: $X_{G}>0$ (good project) and $X_{B}<0$ (bad project).

The probability $p$ of developing a good project depends positively on the effort $e$ provided by the agent in formulating projects and in analyzing their optimal implementation in the relevant economic environment. In order to keep the analysis simple, we assume $p(e)=e$, and thus $e \in(0,1)$.

The agent is risk-averse, and, for the sake of simplicity, we assume that his utility function takes the following form: $U=W^{\alpha}-\gamma e^{2} / 2$, where $W$ is the wage received by the agent, $\alpha$ is a parameter that takes into account the worker's risk aversion $(0<\alpha<$ 1 , where the degree of risk aversion is decreasing in $\alpha$ ), and $\gamma e^{2} / 2$ represents the disutility of his effort. The agent's reservation utility level is denoted by $\underline{u}$.

The Principal and the Organizational Structure. The principal is risk-neutral, and her utility is given by the revenues from projects minus the wage paid to the agent. She has the possibility of choosing between two organizational structures: delegation and hierarchy. We assume that under both organizational structures, in the considered period of time, agents evaluate a single project, drawn from a common pool.

As argued above, in the delegation system the project is autonomously evaluated by the agent, who decides to implement any project he considers profitable, without any control or interference from the principal. Therefore, with probability $e$, the agent selects and implements a project, whose payoff is equal to $X_{G}$, while with probability $1-e$ a bad project is realized, determining a payoff $X_{B}$.

On the other hand, under the hierarchical structure, the principal actively participates in the selection process, by independently acquiring information and evaluating the projects proposed by the agent. She has the right to approve or reject the proposal made by the agent, and only projects proposed by the agent and approved by the principal are implemented. 
The principal is able to recognize with a certain probability the true nature of the project, deciding whether the effective payoff is positive or negative. For the sake of simplicity, we firstly examine the case in which the screening ability of the principal, $s$, is exogenously given, and in sections 3.4 and 5.2 we extend our analysis to consider $s$ as an endogenous variable. When $s$ is exogenous, without loss of generality, we assume that the cost of the principal's activity is equal to zero. With probability $s$ the principal discovers the real nature of the project, approving a good project or rejecting a bad one, while with probability $1-s$ she takes a wrong decision, approving a bad project (Type II error) or refusing a good one (Type I error). Table 1 shows the four possible cases with the corresponding probabilities (recall that the agent proposes a good project with probability $e$ ).

Table 1

Probabilities of Project's Approval or Rejection under Hierarchy

\begin{tabular}{cccc}
\hline Quality of the project & Principal's decision & Probability & Error type \\
\hline good $\left(X_{G}\right)$ & approve & $s e$ & \\
$\operatorname{good}\left(X_{G}\right)$ & reject & $(1-s) e$ & I \\
bad $\left(X_{B}\right)$ & reject & $s(1-e)$ & \\
$\operatorname{bad}\left(X_{B}\right)$ & approve & $(1-s)(1-e)$ & II \\
\hline
\end{tabular}

Hierarchy increases Type I errors, since the principal with probability $1-s$ erroneously rejects good projects proposed by the agent, but it reduces the frequency of Type II errors, because more bad projects are rejected. Both types of errors decrease with a higher level of the principal's ability s.

The importance of Type I errors and Type II errors depends on the values taken by $X_{G}$ and $X_{B}$. Some jobs, such as research, are characterized by a very high $X_{G}$ and a low $\left|X_{B}\right|$ : a new discovery can produce huge profits, but the bad outcome is limited to having no idea. In the terminology of JACOBS [1981], these are star jobs. On the other hand, in some jobs, such as piloting a plane, the good results are limited (a smooth landing), while the bad results can be tremendous (crashing the plane). These are called guardian jobs. A decentralized structure is, ceteris paribus, more efficient in a star job, while hierarchy performs better in a guardian job. However, different results might emerge with endogenous levels of effort. For example, if it is possible to obtain a large effort from the agent employed in a guardian job, it may be not convenient to require a further check by a superior. In what follows we discuss these aspects in greater detail. 


\subsection{Perfect Information and First-Best Effort}

Assuming that the agent's effort is perfectly observable and verifiable and that a complete contract can be written and enforced, we determine the first-best level of effort under both organizational structures. The agent is compensated for his observable effort with a constant wage.

Optimal Effort under Decentralization. Under delegation, it is possible to obtain a positive payoff equal to $X_{G}$ when the agent chooses, with probability $e$, a good project, and a negative payoff $X_{B}$ when he chooses, with probability $1-e$, a bad project. The joint expected welfare of the boss and her subordinate, $S^{D}$ (where superscript $D$ denotes decentralization), is equal to the firm's expected profits plus the agent's utility, that is,

$$
S^{D}=e X_{G}+(1-e) X_{B}-\frac{\gamma e^{2}}{2},
$$

since the wage paid by the firm is equal to the wage certainty equivalent. From the first-order condition $\partial S^{D} / \partial e=0$ we obtain ${ }^{5}$

$$
e_{F B}^{D}=\frac{X_{G}-X_{B}}{\gamma} .
$$

The expression (2) gives the optimal level of effort under decentralization of authority, which is (i) increasing in the positive payoff $X_{G}$, that is, in the profitability of good projects; (ii) increasing in the negative payoff $\left|X_{B}\right|$ (if losses from bad projects are larger, it is efficient to increase effort to avoid them); (iii) decreasing in $\gamma$, since effort is more costly when disutility increases.

Optimal Effort under Hierarchy. Under centralization, it is possible to obtain a positive payoff $X_{G}$ when the agent proposes a good project that is recognized as good by the principal, and a negative payoff $X_{B}$ when the agent proposes a bad project that is implemented because the principal does not recognize it as such (see Table 1 for the probabilities). The projects proposed by the agent and refused by the principal are not implemented, leading to a payoff equal to zero. As a consequence, the total expected welfare $S^{H}$ (where $H$ denotes hierarchy) is equal to

$$
S^{H}=s e X_{G}+(1-e)(1-s) X_{B}-\frac{\gamma e^{2}}{2} \text {. }
$$

From the first-order condition $\partial S^{H} / \partial e=0$ the agent's optimal level of effort is then

$$
e_{F B}^{H}=\frac{s X_{G}-(1-s) X_{B}}{\gamma} .
$$

\footnotetext{
${ }^{5}$ Under our assumptions, the second-order conditions for a maximum are respected.
} 
Analogously to decentralization, the optimal effort is increasing in $X_{G}$ and in $\left|X_{B}\right|$, but is decreasing in $\gamma$.

It is easy to show, comparing the expressions (2) and (4), that the efficient level of effort under delegation is always higher than under hierarchy $\left(e_{F B}^{D}>e_{F B}^{H}\right)$.

This result is similar to that of GEHRIG [2004], who, in a different setup, endogenizing agents' effort in information acquisition, shows that the decentralized system might have an advantage in generating information. As a consequence, Sah and Stiglitz's ranking of decisional rules may change completely, with decentralized systems performing better than hierarchies even in contexts in which Type II errors are particularly relevant (see section 3.3 below).

\subsection{The Relation between the Agent's Effort and the Principal's Ability}

Under hierarchy the agent's effort is increasing in $s$ (that is, the principal's ability is complementary to the agent's effort) if $X_{G}+X_{B}>0$, and decreasing in $s$ (that is, the principal's ability is a substitute for the agent's effort) if $X_{G}+X_{B}<0$. To explain this result, it is helpful to note that if $X_{G}+X_{B}>0$, this implies that the gains from good projects are more important than the losses from bad projects. Since under hierarchy good projects need a double approval to be implemented, it is optimal to encourage high effort when the principal has high ability. On the one hand, the agent's effort in selecting good projects would be lost if the principal were not able to recognize that the selected projects are good; on the other hand, a principal with high ability could not implement good projects if the agent did not propose them. As discussed by JACOBS [1981], the agent's effort is input for the principal's activity and can produce a positive result only if the principal's screening ability is sufficiently high.

On the other hand, when $X_{G}+X_{B}<0$, it means that it is more important to avoid big losses arising from bad projects than to select good projects. In order to reject bad projects it is sufficient that either the principal or the agent is able to recognize them: bad projects are refused whenever the agent or the principal expects a negative payoff, and therefore in this case the principal's ability and the agent's effort are substitutes. Therefore, when the principal's screening ability is high, stimulating the agent's effort is less convenient, since in this case the main role is played by the principal, who is able to recognize bad projects. Only if the principal's screening ability is low is it worthwhile to require a large effort from the agent, in order to avoid losses arising from bad projects.

In short, the optimal agent's effort can come out high when the principal's ability is high and $X_{G}>\left|X_{B}\right|$, or when the principal's ability is low and $X_{G}<\left|X_{B}\right|$.

This result provides some important insights into the relationship existing between the incentives firms need to offer respectively to managers and subordinates, in more general contexts in which the principal's screening activity depends on her effort. According to our results, when the main aim is to avoid the erroneous rejection of good ideas (Type I errors), it is optimal to stimulate both the manager's and the employees' effort. Giving strong incentives to the manager (in order to increase $s$ ) is 
not efficient when adequate incentives for employees are lacking. On the other hand, when the main objective is to avoid big losses (Type II errors), it is sufficient for firms to offer high-powered incentives to just one of the subjects involved in the selection process (typically to the subject showing lower disutility from effort).

\subsection{An Efficiency Comparison between Hierarchy and Delegation under Perfect Information}

In order to evaluate the relative efficiency of the two organizational forms, let us compare the expected welfare obtained under each of them by substituting the corresponding optimal effort in equations (1) and (3). The expected welfare obtained under delegation is equal to

$$
S^{D}=\frac{\left[X_{G}-X_{B}\right]^{2}}{2 \gamma}+X_{B},
$$

and the welfare realized under hierarchy is equal to

$$
S^{H}=\frac{\left[s X_{G}-(1-s) X_{B}\right]^{2}}{2 \gamma}+(1-s) X_{B} .
$$

While the approach based on exogenous levels of effort (see SAH AND STIGLITZ [1986] simply considers hierarchy as more effective in minimizing Type II errors and delegation more effective in avoiding Type I errors, in our framework it is also necessary to consider both the principal's ability and the variables determining the agent's optimal effort. As in SAH AND STIGLITZ [1986], it emerges that the advantage of hierarchy over delegation decreases as $X_{G}$ increases, while a high $\left|X_{B}\right|$ increases the advantage of hierarchy only when $s$ is sufficiently high. ${ }^{6}$ In fact, the negative expected profits deriving from the implementation of bad projects are lower in hierarchy than in delegation only when the higher effort provided by the agent under delegation is not sufficient to compensate for the principal's screening activity.

The principal's screening ability plays a crucial role in strengthening the relative efficiency of hierarchy, since $s$ increases the probabilities of approving good projects and rejecting bad ones. ${ }^{7}$

Finally, the relative efficiency of hierarchy, which requires a lower level of effort, increases with the cost of effort. Since it can be assumed that the cost of the agent's effort is a decreasing function of his ability and education (see, for example, the signaling model of Spence), delegation systems perform better when the workforce is characterized by high levels of education.

\footnotetext{
${ }^{6}$ Defining $F=S^{H}-S^{D}$, the first derivative of $F$ respect to $X_{G}$ is negative $\left(\partial F / \partial X_{G}=X_{G}\left(s^{2}\right.\right.$ $\left.-1)-X_{B}[s(1-s)-1]<0\right)$, while the derivative of $F$ respect to $X_{B}$ has an ambiguous sign depending on $s\left(\partial F / \partial X_{B}=X_{G}[1-s(1-s)]-s(2-s) X_{B}-\gamma s\right)$.

${ }^{7}$ In fact, it is easy to show that $\partial S^{H} / \partial s>0$.
} 


\subsection{The Endogenous Determination of s}

In this section we consider the variable $s$ (the principal's ability) as an endogenous (continuous) variable, interpreting it as the principal's effort in evaluating the projects proposed by the agent. The aim of this extension is to show that this assumption does not change our results in a qualitative way. We consider, under perfect information, the problem of a manager-owner who has to decide his own level of effort $s$ in order to maximize profits.

The total expected welfare $S^{H}$ under hierarchy (given by (3)) is modified by considering the cost of the principal's effort, represented by the function $\lambda s^{2} / 2$ :

$$
S^{H}=s e X_{G}+(1-e)(1-s) X_{B}-\frac{\gamma e^{2}}{2}-\frac{\lambda s^{2}}{2} .
$$

The principal's optimal effort $s$ is obtained from the first-order condition $\partial S^{H} / \partial s=0$ :

$$
s_{F B}=\frac{e X_{G}-(1-e) X_{B}}{\lambda} .
$$

Note that $s_{F B}$ is always positive (recall that $X_{B}<0$ ), and it is less than 1 under the assumption that $\lambda>e X_{G}-(1-e) X_{B}$.

The agent's optimal effort (4) remains unchanged. By substituting (4) in (8), we obtain

$$
S_{F B}=\frac{-X_{B}\left[\left(X_{G}+X_{B}\right)+\gamma\right]}{\left[\lambda \gamma-\left(X_{G}+X_{B}\right)^{2}\right]} .
$$

From (9), it can be shown that $s_{F B}$ is inversely related to the parameter $\lambda$ (which determines the cost of the principal's effort). If $\lambda$ is high (for example, because the manager is overloaded with tasks), $s$ tends to be small, and from the comparison of surpluses (see below) we find that delegation tends to be more efficient than hierarchy (ceteris paribus). On the other hand, if $\lambda$ is small, $s$ will be high and hierarchy tends to prevail over delegation.

In the extreme case in which the parameters in (9) are such that $s_{F B}$ is equal to 1 , we can infer that hierarchy is always more efficient than delegation. On the other hand, when $s$ tends to zero, delegation performs better than hierarchy. This result is similar to that obtained by GEHRIG, REGIBEAU, AND ROCKETT [2000] when the hierarchical system decides to ignore one of the available signals. Nevertheless, in our framework $s$ tending to zero does not imply that the hierarchical system ignores the signal obtained by the principal, but that her screening activity will be qualitatively very poor.

\section{Moral Hazard, Incentives, and Organizational Structure}

In section 3 it was shown, assuming perfect observability, that under delegation it is optimal to require a higher level of effort of the agent. However, in many situations 
the agent's effort is not contractible: it is scarcely observable by the principal or verifiable by an external authority. In these cases, the agent is tempted to behave opportunistically and must be encouraged to provide effort through appropriate incentive contracts. We aim to study how moral hazard and incentive contracts are influenced by the firm's organizational design.

Under both structures, the compensation scheme used by the firm to give incentive to the agent consists of paying him a remuneration related to the outcomes realized through the implementation of projects, which are assumed fully verifiable. ${ }^{8}$ In order to simplify the analysis, we assume that the firm cannot impose the payment of a fine on its workers. This means that a wage equal to zero represents the severest punishment for workers in the case of bad performance. The exclusion of penalties is quite realistic, since workers are usually liquidity-constrained (because of imperfect capital markets) and since legal constraints prevent the possibility of paying a negative wage. ${ }^{9}$

Since workers are risk-averse and outcomes are stochastic, the performancerelated pay system makes it costly to provide incentives and prevents the attainment of first-best solutions. We show that with risk-averse workers (and nonnegative wages), the wage costs related to the compensation scheme are different for the two organizational structures.

Incentive Contracts under Decentralized Decision-Making. Under delegation, the agent has the authority to choose and implement any project he considers profitable. The incentive scheme designed by the firm consists of the payment of a wage $w_{D}$ when a good project is realized (and hence a positive profit is obtained) and a wage equal to zero when a bad project is implemented. ${ }^{10}$

As a consequence, the worker's expected utility $U$ is given by the utility deriving from obtaining the bonus $w_{D}$, which occurs with probability $e$ (the probability that under delegation a good project is realized), minus the cost deriving from the disutility of effort:

$$
U=e\left(w_{D}\right)^{\alpha}-\frac{\gamma e^{2}}{2} .
$$

By maximizing the utility function with respect to the effort $e$, the agent's reaction function can be derived from the first-order condition:

\footnotetext{
${ }^{8}$ In a preliminary version of this paper, consistently with some empirical evidence, we studied the effects of two different incentive systems: performance-related pay in decentralized systems, and compensation based on a subjective performance evaluation made by the principal in hierarchical systems. These assumptions, however, do not lead to relevant changes in our results. Eventually, we chose to consider a homogeneous compensation method to make the comparison between hierarchy and delegation clearer.

${ }^{9}$ This assumption is not crucial for our results, but helps in simplifying calculations.

${ }^{10}$ This contract is equivalent to a performance-related pay contract where the wage is determined as a percentage $\beta$ of the realized output.
} 


$$
e=\frac{\left(w_{D}\right)^{\alpha}}{\gamma} \text {. }
$$

From the reaction function (11) it is useful to determine the wage the firm has to pay for any given level of effort:

$$
w_{D}=(\gamma e)^{1 / \alpha} .
$$

Given the assumption that the wage must always be nonnegative, it follows that the participation constraint is not generally binding. ${ }^{11}$ Therefore, we assume that $U>\underline{u}$ and ignore the participation constraint.

The firm's profit function is given by the expected revenues minus the worker's expected wage $\left(e w_{D}\right)$ :

$$
\Pi^{D}=e X_{G}+(1-e) X_{B}-e w_{D} .
$$

By substituting (12) in $\Pi^{D}$, we get

$$
\Pi^{D}=e X_{G}+(1-e) X_{B}-e[\gamma e]^{1 / \alpha} .
$$

From the first-order condition $\partial \Pi^{D} / \partial e=0$, the level of effort that maximizes profits is found to be equal to

$$
e^{D}=\frac{1}{\gamma}\left[\frac{\alpha\left(X_{G}-X_{B}\right)}{1+\alpha}\right]^{\alpha} .
$$

Because of the greater costs deriving from the compensation system under moral hazard and risk aversion, this second-best level of effort is strictly lower than the first-best level (2).

Incentive Contracts under Centralization of Authority. Under centralization the agent receives a bonus $w_{H}$ when the project he proposes is implemented with positive results, and a wage equal to zero both in the case of negative profits (when a bad project is erroneously realized) and whenever the manager rejects the suggested project. The worker's expected utility in hierarchy is equal to

$$
U=s e\left(w_{H}\right)^{\alpha}-\frac{\gamma e^{2}}{2},
$$

where the first term represents the expected wage.

From the first-order condition, the optimal choice of effort for the agent, given the wage, is obtained:

$$
e=\frac{s\left(w_{H}\right)^{\alpha}}{\gamma} .
$$

The wage the firm has to pay to get the effort $e$ is equal to

$$
w_{H}=\left(\frac{r e}{s}\right)^{1 / \alpha} .
$$

${ }^{11}$ This is a typical result of the efficiency-wage approach (see, for example, TIROLE [1988]). 
It is important to note that the effort that the agent decides to provide is increasing in the principal's ability s or, alternatively, that a low-ability principal must pay a higher bonus to stimulate the agent's effort.

Comparing the expressions (12) and (18), it emerges that $w_{H}>w_{D}$ : under a hierarchical system, in order to elicit a given amount of effort, it is necessary to pay a higher bonus than under delegation as long as $s<1$. $^{12}$

The firm's expected profits in hierarchy are equal to

$$
\Pi^{H}=s e\left(X_{G}\right)+(1-e)(1-s)\left(X_{B}\right)-s e\left(\frac{\gamma e}{s}\right)^{1 / \alpha},
$$

where (19) takes into account the wage (18) paid with probability se. The level of effort desired by the firm is derived from the condition $\partial \Pi^{H} / \partial e=0$ :

$$
e^{H}=\frac{1}{\gamma} s^{1-\alpha}\left[\frac{\alpha\left[s X_{G}-(1-s) X_{B}\right]}{1+\alpha}\right]^{\alpha} .
$$

It clearly emerges that the effort required by the firm is below the first-best level: $e^{H}$ $<e^{H}$ FB.

Since, from comparing (20) with (15), it emerges that the level of effort required by the hierarchical system is lower than that for delegation $\left(e^{H}<e^{D}\right)$, it follows that, as long as the principal's screening ability is not perfect, the hierarchical system pays a higher bonus and requires a lower effort than delegation.

\section{The Organizational Choice with Discrete Levels of Effort}

An efficiency comparison between delegation and hierarchy is very complex because, besides the differing incidence of good and bad projects, as we have seen in section 3 , the wage cost necessary to induce the agent to provide effort also differs, and thus the levels of effort chosen under the two structures differ too.

In this section we aim to compare benefits and costs deriving from the two organizational structures, neutralizing the effects arising from the choice of different levels of effort. This can be done by assuming that the effort is a discrete variable, which can take only two values: a high effort $e_{h}$, or a low effort $e_{l}$, where $e_{h}>e_{l}$. The assumptions previously made are modified as follows. When the agent chooses high effort, the probability of formulating a good project (profit $X_{G}$ ) is equal to $p_{h}$, while with probability $1-p_{h}$ the project yields a negative profit $X_{B}$. If instead the agent's effort is low, then the probability of realizing a good project is equal to $p_{l}$, and that of realizing a bad project is $1-p_{l}$, with $p_{h}>p_{l}$. The worker's disutility cost of providing

\footnotetext{
${ }^{12}$ The bonus would be equal to that paid under delegation only if $s=1$ (perfect screening ability).
} 
high effort is equal to $c_{h}$, and his disutility of low effort is equal to $c_{l}$, where $c_{h}>c_{l}{ }^{13}$ The other assumptions remain unchanged.

Incentive Contracts under Delegation. When the agent provides a high level of effort, with probability $p_{h}$ a good project is implemented and the agent obtains a wage equal to $w_{D}$, while if the project, with probability $1-p_{h}$, is unsuccessful, his wage is equal to zero. The agent decides to exert high effort only as long as the utility deriving from it is higher than the utility deriving from low effort, that is, when the following incentive-compatibility constraint is satisfied:

$$
p_{h} w_{D}^{\alpha}-c_{h} \geq p_{l} w_{D}^{\alpha}-c_{l} .
$$

The incentive compatibility implies that the firm must pay a bonus $w_{D}$ equal to

$$
w_{D}=\left[\frac{c_{h}-c_{l}}{p_{h}-p_{l}}\right]^{\frac{1}{\alpha}} .
$$

The bonus $w_{D}$ is increasing in the difference $c_{h}-c_{l}$, is decreasing in the difference $p_{h}$ $-p_{l}$, and increases when the worker's degree of risk aversion increases (that is, when $\alpha$ decreases). ${ }^{14}$

The agent's participation constraint is the following: $p_{h} w_{D}{ }^{\alpha}-c_{h} \geq \underline{u}$, where $\underline{u}$ represents the agent's reservation utility. As explained above, we suppose that, given the impossibility of imposing a negative wage, the utility the individual obtains by providing high effort is higher than his reservation utility and that therefore his participation constraint is not binding.

The profits obtained by the firm under delegation, using (22), are equal to

$$
\Pi^{D}=p_{h} X_{G}+\left(1-p_{h}\right) X_{B}-p_{h}\left[\frac{c_{h}-c_{l}}{p_{h}-p_{l}}\right]^{\frac{1}{\alpha}} \text {. }
$$

Incentive Contracts under Hierarchy. Under the hierarchical system, proposing good projects does not yield any positive payoff for the agent if the principal does not approve them. Given the compensation scheme, the agent's expected payoff depends on the principal's ability to find out the true nature of the suggested project. Then, under hierarchy, the agent's incentive-compatibility constraint is the following:

$$
p_{h} s w_{H}{ }^{\alpha}-c_{h} \geq p_{l} s w_{H}{ }^{\alpha}-c_{l},
$$

where $w_{H}$ is the bonus paid to the agent when a good project is realized.

From (24), the bonus $w_{H}$ the firm has to pay to encourage the agent is given by

\footnotetext{
${ }^{13}$ Moreover, by assumption the total surplus and the firm's profit obtained when the worker provides high effort are always greater than those realized when he provides low effort.

${ }^{14}$ The expression in brackets is assumed to be greater than 1 .
} 


$$
w_{H}=\left[\frac{c_{h}-c_{l}}{s\left(p_{h}-p_{l}\right)}\right]^{\frac{1}{\alpha}} \text {. }
$$

$w_{H}$ is decreasing in $s$, and is found to be higher than the optimal bonus under delegation.

It can be shown from (22) and (25) that the agent's expected wage under hierarchy, $p_{h} S w_{H}$, is greater than his expected wage under delegation, $p_{h} w_{D}$ :

$$
s p_{h}\left[\frac{c_{h}-c_{l}}{s\left(p_{h}-p_{l}\right)}\right]^{\frac{1}{\alpha}} \geq p_{h}\left[\frac{c_{h}-c_{l}}{p_{h}-p_{l}}\right]^{\frac{1}{\alpha}},
$$

since $s<1$ and $\alpha<1$. This is a crucial result of our analysis: under hierarchy it is necessary to pay a higher wage than under delegation to elicit the same level of effort. Since principal's activity reduces the probability of implementing good projects and, as a consequence, the agent's probability of obtaining a high wage, in order to motivate him to exert effort, the payment of a higher bonus is required. With risk aversion, this implies higher costs for the firm.

The firm's profits under hierarchy are equal to

$$
\Pi^{H}=p_{h} s X_{G}+\left(1-p_{h}\right)(1-s) X_{B}-s p_{h}\left[\frac{c_{h}-c_{l}}{s\left(p_{h}-p_{l}\right)}\right]^{\frac{1}{\alpha}} .
$$

\subsection{The Relative Efficiency of Hierarchy and Delegation}

An efficiency comparison between the centralized and the decentralized organizational form can be realized by considering the total surpluses (equal to the firm's expected profits plus the worker's certainty equivalent) deriving from each of them. ${ }^{15}$ The total surplus under hierarchy is the following:

(28) $S^{H}=p_{h} s X_{G}+\left(1-p_{h}\right)(1-s) X_{B}-p_{h} s\left[\frac{c_{h}-c_{l}}{s\left(p_{h}-p_{l}\right)}\right]^{\frac{1}{\alpha}}+\left(p_{h} s\right)^{\frac{1}{\alpha}}\left[\frac{c_{h}-c_{l}}{s\left(p_{h}-p_{l}\right)}\right]^{\frac{1}{\alpha}}-c_{h}$.

Similarly, under delegation the total surplus is given by

$$
S^{D}=p_{h} X_{G}+\left(1-p_{h}\right) X_{B}-p_{h}\left[\frac{c_{h}-c_{l}}{p_{h}-p_{l}}\right]^{\frac{1}{\alpha}}+\left(p_{h}\right)^{\frac{1}{\alpha}}\left[\frac{c_{h}-c_{l}}{p_{h}-p_{l}}\right]^{\frac{1}{\alpha}}-c_{h} .
$$

In order to compare the efficiency of the two systems it is useful to give a graphical representation of the combinations of $X_{G}$ and $s$ that equalize the surpluses generated

\footnotetext{
${ }^{15}$ Since under the two structures the worker gets the same certainty equivalent, identical results would emerge if one compared the firm's profits. In fact, the agent's certainty equivalent $E C$ satisfies $u(E C)=U A$, where $U A$ is the agent's expected utility. Under delegation $\left(E C_{D}\right)^{\alpha}=p_{h}\left(w_{D}\right)^{\alpha}$, from which $E C_{D}=p_{h}{ }^{1 / \alpha} w_{D}$, while under hierarchy $\left(E C_{H}\right)^{\alpha}=$ $s p_{h}\left(w_{H}\right)^{\alpha}$, that is, $E C_{H}=\left(s p_{h}\right)^{1 / \alpha} w_{H}$. Substituting (22) and (25) respectively for $w_{D}$ and $w_{H}$, it is possible to ascertain that $E C_{H}=E C_{D}$.
} 
under the two systems. Therefore, imposing $S^{H}=S^{D}$ from (28) and (29), the threshold values of $\bar{X}_{G}$ as a function of $s$ can be expressed as

$$
\bar{X}_{G}=-\frac{s\left(1-p_{h}\right)}{(1-s) p_{h}} X_{B}-\frac{\frac{1}{s^{(1-\alpha) / \alpha}}-1}{1-s}\left[\frac{c_{h}-c_{l}}{p_{h}-p_{l}}\right]^{\frac{1}{\alpha}} \text {. }
$$

On the basis of (30) it is possible to draw (see Figure 1) an organizational equivalence curve (OEC hereafter), which represents the threshold values of $\bar{X}_{G}$ (on the vertical axis) and $s$ (on the horizontal axis). ${ }^{16}$ We note that $\partial \bar{X}_{G} / \partial s>0$; when $s$ tends to $1, \bar{X}_{G}$ tends to $+\infty$; when $s$ tends to $0, \bar{X}_{G}$ tends to $-\infty$; and the sign of $\partial^{2} \bar{X}_{G} / \partial s^{2}$ depends on the value of $s$ (the function is concave for low $s$, and convex for high $s){ }^{17}$

\section{Figure 1}

A Comparison between Hierarchy and Delegation as a Function of $s$ and $X_{G}$

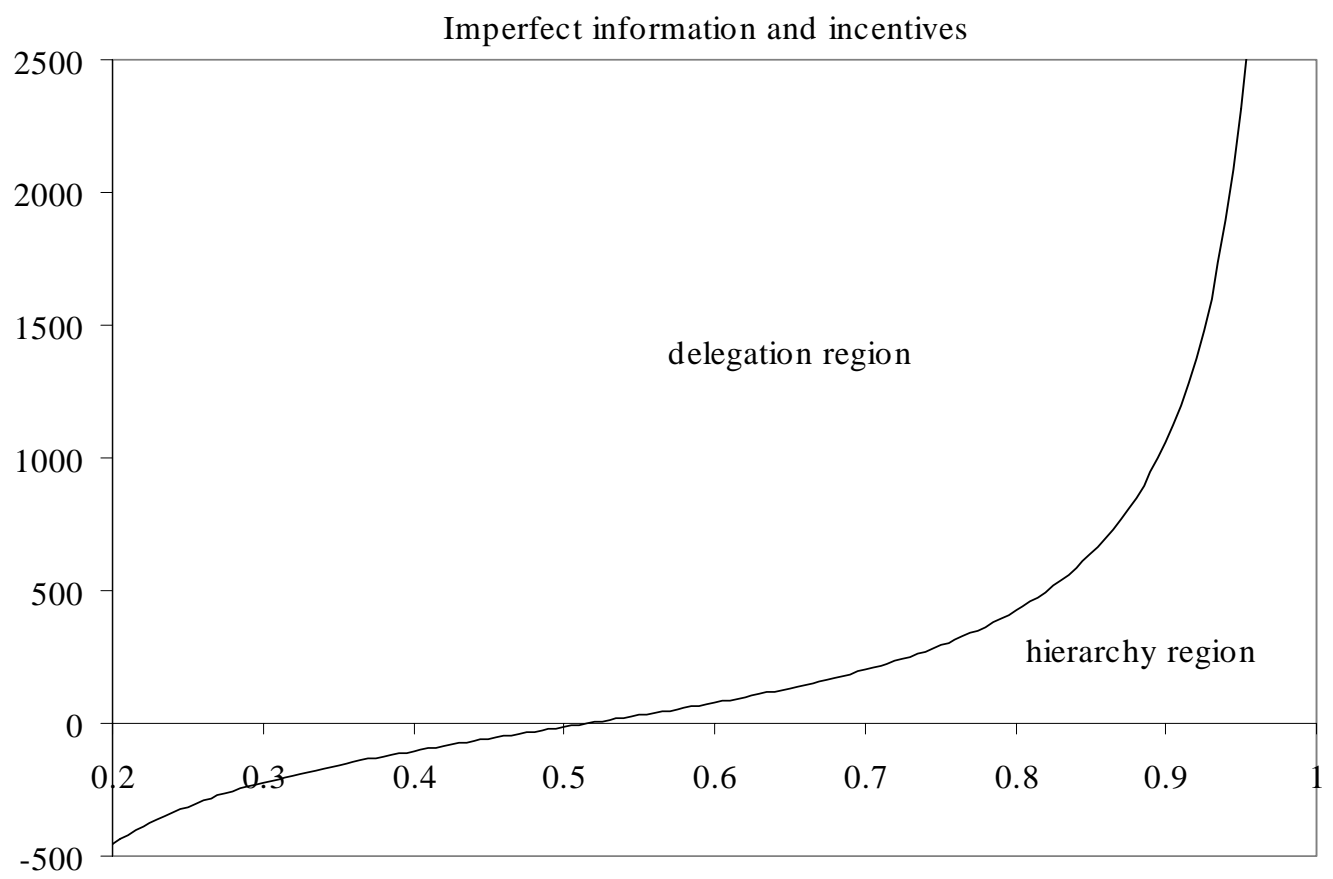

\footnotetext{
${ }^{16}$ Figure 1 is drawn assuming $X_{B}=-500 ; p_{H}=0.8 ; p_{L}=0.1 ; c_{H}=4 ; c_{L}=1 ; \alpha=0.4$.

${ }^{17}$ See Appendix for demonstrations.
} 
The advantages of hierarchy increase with the principal's screening ability $s$, both because of better selection of projects and because the agent's effort becomes less costly (when $s$ tends to 1 , the cost of obtaining the high effort is almost the same under the two organizational forms). Therefore, an increase in $s$ requires, in order to maintain the equality of surpluses between the two systems, a higher value of $X_{G}$ (which favors delegation, since it increases the relative importance of Type I errors).

Figure 1 shows how the relative efficiency of hierarchy and delegation changes with $X_{G}$ and $s$. The OEC demarcates two regions: all the combinations of $X_{G}$ and $s$ lying above the OEC represent situations in which delegation generates a higher surplus than hierarchy $\left(S^{D}>S^{H}\right)$ and thus belong to the delegation region; in contrast, the area below the OEC represents combinations of $X_{G}$ and $s$ in which hierarchy performs better $\left(S^{H}>S^{D}\right)$, defining a hierarchy region.

The position of OEC depends, among others things, on the values of the variables $\left|X_{B}\right|, c_{h}$, and $\alpha$. A higher $\left|X_{B}\right|$, reducing the relative advantage of delegation, shifts the OEC upward, expanding the region in which hierarchy is more efficient. An opposite result is obtained when the agent's effort is more costly. In this case, stronger incentives are necessary, which in turn increase the relative inefficiency of the hierarchical system. Finally, the relative performance of the hierarchical system worsens (and the OEC moves downward) when the agent's risk aversion is higher, because providing incentives becomes more costly: $\partial X_{G} / \partial \alpha>0$ (see Appendix).

These results show that in some contexts it may be convenient to rely on a single observation and neglect the further information provided by the principal. Under perfect information, a similar result is obtained by GEHRIG, REGIBEAU, AND ROCKETT [2000], considering endogenous threshold rules, and by GEHRIG [2004] in a model with endogenous information acquisition. We show that these effects are even strengthened in contexts with asymmetric information.

The Organizational Performance under Perfect and Imperfect Information. In order to compare the performance of the organizational forms under the assumption of unobservable agent's effort and incentive contracts with the performance in a perfectinformation context, we derive an OEC under the hypothesis that effort is perfectly contractible. In this case, taking into account that the wage paid by the firm coincides with the wage certainty equivalent obtained by the agent, the total surpluses in hierarchy $\left(\tilde{S}^{H}\right)$ and delegation $\left(\tilde{S}^{D}\right)$ are respectively equal to

$$
\begin{gathered}
\tilde{S}^{H}=p_{h} s X_{G}+\left(1-p_{h}\right)(1-s) X_{B}-c_{h}, \\
\tilde{S}^{D}=p_{h} X_{G}+\left(1-p_{h}\right) X_{B}-c_{h} .
\end{gathered}
$$

Starting from the condition $\tilde{S}^{H}=\tilde{S}^{D}$, we can find out the values of $X_{G}$ and $s$ that make the firm indifferent between the two organizational forms:

$$
\tilde{X}_{G}=-\frac{s\left(1-p_{h}\right)}{p_{h}(1-s)} X_{B} .
$$


The OEC based on (33) and the OEC with incentive contracts [based on (30)] are drawn in Figure 2. ${ }^{18}$

Figure 2

Organizational Performance with Perfect and Imperfect Information

Organizational Equivalence Curves

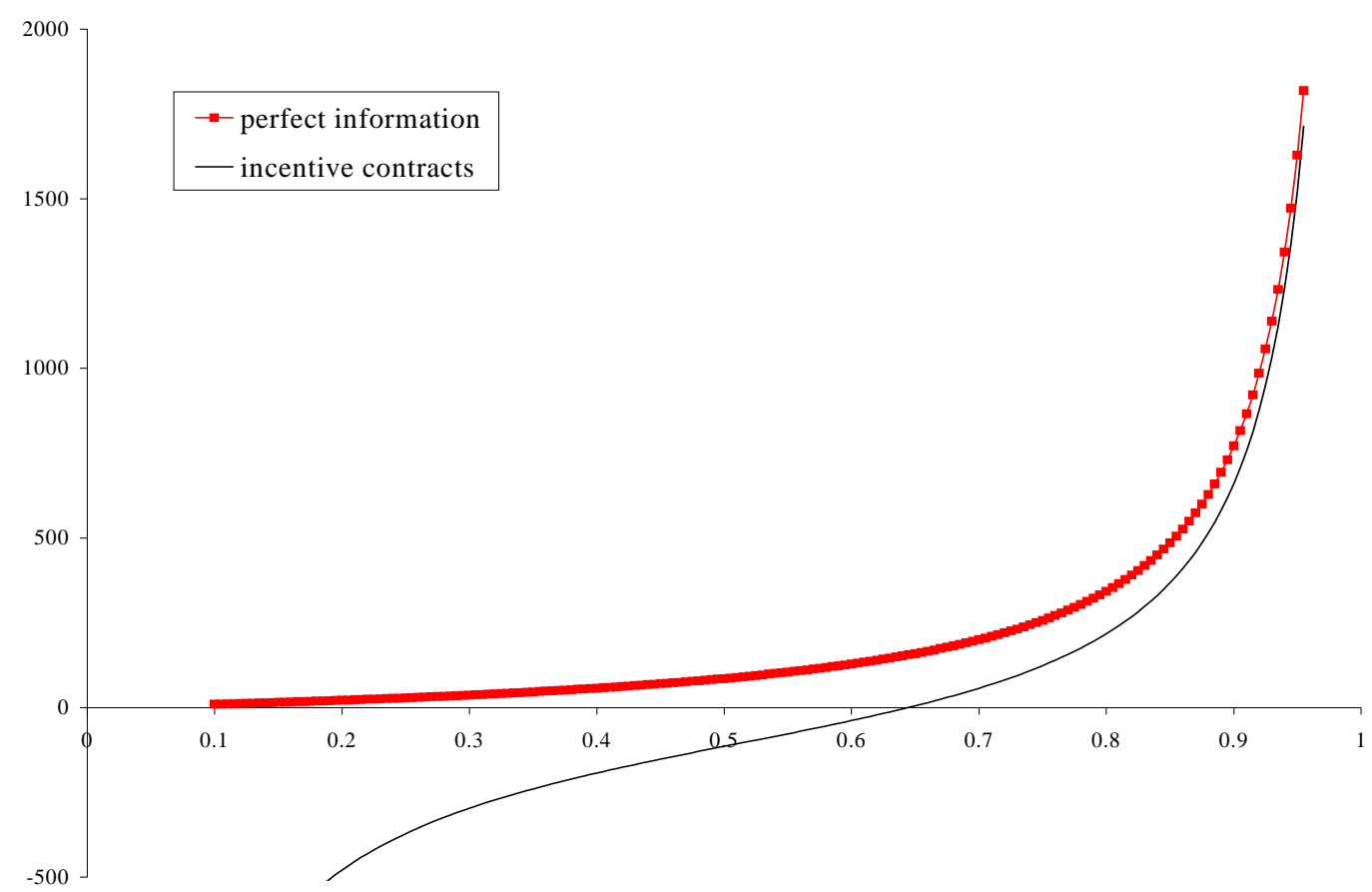

Comparing the OECs with perfect and imperfect information, it is possible to show a fundamental result of our analysis: the decentralized structure is more efficient in dealing with moral-hazard problems. Graphically, this gives rise to an expansion of the delegation region in the case of asymmetric information, so that $\tilde{X}_{G}>\bar{X}_{G}$ for any value of $s$. However, the OEC under asymmetric information approaches the curve under perfect information for high values of $s$, or when $\alpha$ is close to 1 (that is, when the agent is risk-neutral).

\subsection{The Endogenous Determination of s with Moral Hazard and Discrete Levels of Effort}

We now consider the case in which $s$ is endogenous. The principal chooses her level of effort considering, on the one hand, both the positive effect on the expected quality of projects and the reduction in the wage cost necessary to motivate the agent, and, on

\footnotetext{
${ }^{18}$ Figure 2 is drawn assuming $X_{B}=-500 ; p_{H}=0.7 ; p_{L}=0.3 ; c_{H}=5 ; c_{L}=1 ; \alpha=0.4$.
} 
the other hand, the cost of her effort. The principal's utility $U_{P}{ }^{H}$ is obtained as the firm's profits (27) minus the cost of her effort:

$$
U_{P}^{H}=p_{h} s X_{G}+\left(1-p_{h}\right)(1-s) X_{B}-s p_{h}\left[\frac{c_{h}-c_{l}}{s\left(p_{h}-p_{l}\right)}\right]^{\frac{1}{\alpha}}-\frac{\lambda s^{2}}{2} .
$$

From the first-order condition $\partial U_{P}{ }^{H} / \partial s=0$, we have

$$
\left(1-\frac{1}{\alpha}\right) s^{-\frac{1}{\alpha}} p_{h}\left[\frac{c_{h}-c_{l}}{\left(p_{h}-p_{l}\right)}\right]^{\frac{1}{\alpha}}+\lambda s=p_{h} X_{G}-\left(1-p_{h}\right) X_{B} .
$$

Equation (A5) implicitly defines the optimal value of $s$, which we denote by $s^{*}$. The expected welfare of hierarchy is found to be

$$
\begin{aligned}
S^{H}=p_{h} s^{*} X_{G}+\left(1-p_{h}\right)\left(1-s^{*}\right) X_{B} & -p_{h} s^{*}\left[\frac{c_{h}-c_{l}}{s^{*}\left(p_{h}-p_{l}\right)}\right]^{\frac{1}{\alpha}} \\
& +\left(p_{h} s^{*}\right)^{\frac{1}{\alpha}}\left[\frac{c_{h}-c_{l}}{s^{*}\left(p_{h}-p_{l}\right)}\right]^{\frac{1}{\alpha}}-c_{h}-\frac{\lambda s^{* 2}}{2},
\end{aligned}
$$

while the expected welfare under delegation is defined by (29). In this setting, from the condition $S^{H}=S^{D}$, the values of $X_{G}$ and $s$ that make the firm indifferent between the two organizational forms are

$$
\bar{X}_{G}=-\frac{s^{*}\left(1-p_{h}\right)}{\left(1-s^{*}\right) p_{h}} X_{B}-\frac{\frac{1}{s^{*(1-\alpha) / \alpha}}-1}{1-s^{*}}\left[\frac{c_{h}-c_{l}}{p_{h}-p_{l}}\right]^{\frac{1}{\alpha}}-\frac{\lambda s^{* 2}}{2\left(1-s^{*}\right) p_{h}} .
$$

The OEC based on equation (37), and the one under perfect information, ${ }^{19}$ take the same shape as in the case considering an exogenous level of $s$ (Figure 2), but they are shifted downward by the disutility of the principal's effort. Given a certain value of $s^{*}$ from (35), we can proceed to evaluate the relative efficiency of the two organizational forms by using Figure 2. Our qualitative results stated above do not change. However, due to the cost of the principal's effort, the delegation region becomes larger.

\section{Concluding Remarks}

Firms can choose to establish different kinds of hierarchical relationships among subjects participating in the production process. In flatter organizational structures individuals have authority over which projects to implement. In contrast, in

\footnotetext{
${ }^{19}$ This is obtained from $\tilde{S}^{H}=\tilde{S}^{D}$, where $\tilde{S}^{H}=p_{h} S X_{G}+\left(1-p_{h}\right)(1-s) X_{B}-c_{h}-\lambda s^{2} / 2$ and $\tilde{S}^{D}$ is defined by (29). Therefore, the OEC with perfect information is given by $X_{G}=-[(1-$ $\left.\left.p_{h}\right) s X_{B} / p_{h}(1-s)\right]-\left[\lambda s^{2} / 2 p_{h}(1-s)\right]$.
} 
hierarchical systems the superior has the ability to veto decisions made by her subordinates. SAH AND STIGLITZ [1986] show that the choice between these two structures depends on the cost of rejecting good projects compared to the cost of accepting poor ones. This result is obtained assuming an exogenously given project portfolio and agents with identical screening abilities.

In this paper, in a framework similar to that proposed by Sah and Stiglitz, but dealing with problems of divergent objectives between organizations' members, we compare hierarchical and delegation systems under the hypothesis that the agent's probability of identifying good projects depends on his effort.

Considering firstly perfect observability of effort, we show that the optimal effort is higher under delegation. By comparing the total surpluses obtained under the two organizational forms, we demonstrate that the relative efficiency of the systems is related not only to the importance of Type I and Type II errors, but also to the principal's screening ability and to the disutility of the effort.

In the second part of the paper we deal with the problem of moral hazard arising from imperfect observability of effort. In both structures, in order to encourage effort, firms have to provide incentives to the agent with performance-related pay systems. We show that under hierarchy, since the principal's activity reduces both the probability of implementing bad projects (and thus the agent's probability of receiving a negative payoff) and the probability of implementing good projects (and thus the agent's probability of being rewarded), performance-related pay requires higher bonuses and higher penalties to elicit the agent's effort. However, with riskaverse workers this implies more costly incentives in hierarchy than with delegation. Therefore, we show that given the principal's screening ability, the performance of the hierarchical systems worsens in asymmetric-information contexts. This result is similar to that obtained by ZABOJNIK [2002], but instead of being related to the agent's belief in the principal's information, it is due to the principal's imperfect screening of projects proposed by the agent. Moreover, referring to the organizational structures as identified by SAH AND STIGLITZ [1986], we emphasize the role played by Type I and Type II errors in shaping agency relationships.

In our setup, the relative advantage of delegation depends on the degree of observability of effort, on the agent's risk aversion, and on his skills. Since hierarchy introduces greater uncertainty in the agent's payoff, the cost of the incentive system increases with the agent's risk aversion more in hierarchy than with delegation. In addition, as delegation requires higher effort, its performance depends on workers' abilities and education, which determine their effort.

The performance of hierarchy is closely related to the principal's ability, since the agent's effort depends on the principal's interest and ability in evaluating his proposals. The superior might not be interested in carefully reviewing the employees' suggestions and in implementing those that have merit, or he might not have enough information or might be endowed with low ability that does not allow him to recognize good suggestions. The importance of the superior's performance in evaluating his subordinates' suggestions emerges in the practical implementation of 
the systems known as total quality management, continuous improvement, and suggestion box, which require the employees' involvement in increasing the firm's productivity, the quality of its products, and so on. Since employees' suggestions are implemented only if approved by a superior, a key factor for the success of these plans is the superior's ability to recognize good and bad projects. On the other hand, stimulating workers' participation is costly and does not produce positive results when the superior is not interested in carefully reviewing the employees' suggestions and in implementing those that have merit. ${ }^{20}$

Our results are also consistent with other empirical findings and may be useful for interpreting the recent diffusion of new work practices that allow workers greater autonomy in flatter organizations. According to the results of our analysis this may be related to increased importance of costs deriving from the refusal of profitable projects. In economic contexts characterized by more intense competition, high rates of innovation, and frequent external shocks, the ability to innovate represents a key factor for the firm's success, and thus the losses deriving from conservative behavior may be extremely important. On the contrary, in more stable environments, in which the threat of new innovative firms is low, avoiding the implementation of poor projects may be more important (LAZEAR [1998], AOKI [1986]).

The movement of organizations toward greater delegation can also be explained by an increased importance of incentives. Changes in the type of jobs performed by workers, the increased requirement of product quality, the greater difficulties in monitoring employees' effort, the greater weight of the service sector characterized by production of intangibles, are all factors that have made observation of effort more difficult and, hence, moral-hazard problems more severe. The attempt to solve these problems may have led firms to adopt more decentralized organizational forms. This view finds support in the empirical evidence showing that the adoption of decentralized organizational structures is usually accompanied by the introduction of incentive contracts and by the fact that large firms for which moral-hazard problems are more acute tend more frequently to delegate authority to subordinates (OSTERMAN [1994], ICHNIOWSKI AND SHAW [2003], COLOMBO AND DELMASTRO [2004]).

The role of increased levels of workers' education in the diffusion of decentralized forms of organization, discussed in the theoretical analysis, ${ }^{21}$ finds support in the empirical literature showing that greater employee decisional power is associated with the presence of highly skilled workers and high training investment (OSTERMAN [1994], CAROLI AND VAN REENEN [2001]): skilled workers may easily substitute for the screening activity provided by the principal in hierarchical systems.

\footnotetext{
${ }^{20}$ Many scholars in management techniques stress the importance of considering workers' suggestions. EMMERICH [2002, p. 7] writes “According to an Employee Involvement Association study, the average employee in Japan submits 32 ideas for improvement per year, compared with the average employee in the United States who submits 0.17 - a ratio of 1881 . The root of this problem stems from the fact that only 33 percent of U.S. employees' ideas are adopted - compared with 87 percent for those of the Japanese workers.”

${ }^{21}$ On this aspect see also MARSDEN AND RYAN [1991] and SOSKICE [1993].
} 
The type of framework we propose, however, says little about a number of other empirical findings, such as the fact - shown by RAJAN AND WULF [2003] - that flatter organizations tend to pay employees with long-term incentives, such as stock options, stock grants, and promotions. Other evidence from case studies documents a high incidence of managers who renege on the discretion they have delegated to their subordinates (COYLE-SHAPIRO AND KESSLER [2000]).

The static structure of our model does not allow the consideration of sequential decisions and dynamic incentives, and further extensions of the model should take into account the fact that agency relationships tend to repeat over time and outcomes achieved in the current period may influence the agents' behavior in the future. For example, an agent performing particularly well in his evaluation activity might be promoted to become a superior. This would produce two positive effects influencing the efficiency comparison between the two organizational forms: the selection of managers endowed with high abilities, and an incentive for the agent to exert effort. In addition, in a repeated framework, the principal who has to decide whether to accept or reject the project proposed by his subordinate will probably rely both on his own evaluation and on the subordinate's past performance. In the case of activities that produce their effects during many periods, initial negative results may induce the principal to renege on delegation of authority with negative long-run effects. These aspects, while important, require a completely different (dynamic rather than static) setup and are left for future research.

\section{Appendix}

\section{A.1 Section 5.1: The slope of the OEC}

It is possible to see that $\bar{X}_{G}$ increases when $s$ increases. In fact, using the implicitfunction theorem, we have

$$
\frac{\partial X_{G}}{\partial s}=-\frac{\partial F / \partial s}{\partial F / \partial X_{G}}
$$

Since

$$
\frac{\partial F}{\partial s}=p_{H} X_{G}-\left(1-p_{H}\right) X_{B}+\frac{(1-\alpha)}{\alpha} p_{H}\left[\frac{c_{H}-c_{L}}{s\left(p_{H}-p_{L}\right)}\right]^{\frac{1}{\alpha}}>0
$$

is always true and

$$
\frac{\partial F}{\partial X_{G}}=-(1-s) p_{H}<0
$$

is always true, we obtain that

$$
\frac{\partial X_{G}}{\partial s}=-\frac{\partial F / \partial s}{\partial F / \partial X_{G}}>0
$$


The second derivative is equal to

$$
\frac{\partial^{2} X_{G}}{\partial s^{2}}=\frac{p_{H}\left[p_{H} X_{G}-\left(1-p_{H}\right) X_{B}\right]+\left\{p_{H}{ }^{2} \frac{(1-\alpha)}{\alpha}\left[\frac{c_{H}-c_{L}}{s\left(p_{H}-p_{L}\right)}\right]^{\frac{1}{\alpha}}\left[1-\frac{(1-s) p_{H}}{\alpha s}\right]\right\}}{\left[(1-s) p_{H}\right]^{2}} .
$$

The sign of $\partial^{2} X_{G} / \partial s^{2}$ depends on the value of $s$ : it is positive for high values of $s$, which means that the function is convex, and negative for low values, so that the function is concave.

Q.E.D.

\section{A.2 Section 5.1: The Relation between Organizational Performance and Risk Aversion}

The performance of the hierarchical system worsens when the agent's risk aversion is higher. In fact, the sign of the first derivative of the threshold value of $X_{G}$ with respect to $\alpha$ is positive:

$$
\begin{aligned}
& \frac{\partial X_{G}}{\partial \alpha}=\frac{-\alpha^{2}}{1-s}\left[\frac{c_{H}-c_{L}}{\left(p_{H}-p_{L}\right)}\right]^{\frac{1}{\alpha}} \log \left[\frac{c_{H}-c_{L}}{\left(p_{H}-p_{L}\right)}\right] \\
& +\frac{s^{1-1 / \alpha} \alpha^{2}}{1-s}\left[\frac{c_{H}-c_{L}}{\left(p_{H}-p_{L}\right)}\right]^{\frac{1}{\alpha}} \log \left[\frac{c_{H}-c_{L}}{\left(p_{H}-p_{L}\right)}\right] \frac{\alpha^{2}}{1-s}\left[\frac{c_{H}-c_{L}}{\left(p_{H}-p_{L}\right)}\right]^{\frac{1}{\alpha}} \\
& \times\left\{\log \left[\frac{c_{H}-c_{L}}{\left(p_{H}-p_{L}\right)}\right]\left(s^{1-1 / \alpha}-1\right)-s^{1-1 / \alpha} \log s\right\}>0 . \\
& \text { Q.E.D. }
\end{aligned}
$$

\section{References}

Aghion, P., AND J. TIROLE [1997], "Formal and Real Authority in Organizations,” Journal of Political Economy, 105, 1-29.

AOKI, M. [1986], "Horizontal versus Vertical Information Structure of the Firm,” American Economic Review, 76, 971-983.

ATHEY, S., AND J. RoBERTS [2001], “Organizational Design: Decision Rights and Incentive Contracts,” American Economic Review, 91, 200-205.

BAKER, G., R. GiBBONS, AND K. MURPHY [1999], "Informal Authority in Organizations," Journal of Law, Economics, \& Organization, 15, 56-73.

Bolton, P., AND M. DewATRIPONT [1994], "The Firm as a Communication Network," Quarterly Journal of Economics, 109, 809-839.

CAROLI, E., AND J. VAN REENEN [2001], "Skilled Biased Organizational Change? Evidence from a Panel of British and French Establishments," Quarterly Journal of Economics, 116, 1449-1491. 
- -, N. GReEnAN, AND D. Guellec [2001], "Organizational Change and Skill Accumulation," Industrial and Corporate Change, 10, 481-506.

Colombo, M., And M. Delmastro [2004], "Delegation of Authority in Business Organizations: An Empirical Test,” Journal of Industrial Economics, 52, 53-80.

Coyle-ShAPIRO, B., AND J. Kessler [2000], "Consequences of the Psychological Contract for the Employment Contract: A Large-Scale Survey,” Journal of Management Studies, 37, 903-930.

EMMERICH, R. [2002], “The 10 Commandments of Workplace Motivation,” http://www.emmerichgroup.com/html/commandments.htm.

GARICANO, L. [2000], "Hierarchies and the Organization of Knowledge in Production," Journal of Political Economy, 108, 874-904.

GeHRIG, T. [2004], "Organizational Form and Information Acquisition," Journal of Institutional and Theoretical Economics, 160, 1-13.

- - , P. RegiBeAu, AND K. RocKeTt [2000], "Project Evaluation and Organizational Form,” Review of Economic Design, 5, 177-199.

GERSBACH, H., AND U. WEHRSPOHN [1998], "Organizational Design with a Budget Constraint," Review of Economic Design, 3, 149-157.

Grossman, S., AND O. HART [1986], "The Costs and Benefits of Ownership: A Theory of Vertical and Lateral Integration," Journal of Political Economy, 95, 691-719.

HART, O. D., AND J. MOORE [1990], "Property Rights and the Nature of the Firm,” Journal of Political Economy, 98, 1119-1158.

ICHNIOWSKI, C., AND K. SHAW [2003], "Beyond Incentive Pay: Insiders' Estimates of the Value of Complementary Human Resource Management Practices," Journal of Economic Perspectives, 17, 155-180.

JACOBS, D. [1981], "Toward a Theory of Mobility and Behavior in Organizations: An Inquiry into the Consequences of Some Relationships between Individual Performance and Organizational Success," American Journal of Sociology, 87, 684-707.

LAZEAR, E. [1998], Personnel Economics for Managers, John Wiley \& Sons: New York.

MARSDEN, D., AND P. RYAN [1991], "Initial Training Labour Market Structure and Public Policy: Intermediate Skills in British and German Industry,” pp. 251-285 in: P. Ryan (ed.), International Comparisons of Vocational Education and Training for Intermediate Skills, Falmer Press: London.

OSTERMAN, P. [1994], "How Common Is Workplace Transformation and Who Adopts it?" Industrial and Labor Relations Review, 47, 173-187.

PRENDERGAST, C. [2002], “The Tenuous Trade-Off between Risk and Incentives,” Journal of Political Economy, 110, 1071-1102.

RADNER, R. [1992], "Hierarchy: The Economics of Managing," Journal of Economic Literature, 30, 1342-1415.

RAJAN, R., AND J. WULF [2003], "The Flattening Firm: Evidence from Panel Data on the Changing Nature of Corporate Hierarchies,” NBER Working Paper 9633.

SAH, R., AND J. STIGLITZ [1986], "The Architecture of Economic Systems: Hierarchies and Polyarchies,” American Economic Review, 76, 716-727.

- - AND - - [1988], “Committees, Hierarchies and Polyarchies,” Economic Journal, 98, 451470.

SoskiCE, D. [1993], "Social Skills from Mass Higher Education: Rethinking the CompanyBased Initial Training Paradigm,” Oxford Review of Economic Policy, 9, 101-113. 
STEIN, J. [2002], "Information Production and Capital Allocation: Decentralized versus Hierarchical Firms,” Journal of Finance, 57, 1891-1921.

TIROLE, J. [1988], The Theory of Industrial Organization, MIT Press: Cambridge, MA.

VAN ZANDT, T. [1999], "Real-Time Decentralized Information Processing as a Model of Organizations with Boundedly Rational Agents,” Review of Economic Studies, 66, 633658.

ZABOJNIK, J. [2002], “Centralized and Decentralized Decision Making in Organizations,” Journal of Labor Economics, 20, 1-22.

Maria De Paola

Vincenzo Scoppa

Dipartimento di Economia e Statistica

Università della Calabria

Arcavacata di Rende

87036 Cosenza

Italy

E-mail:

m.depaola@unical.it

v.scoppa@unical.it 